\title{
Study of oils from the protected denomination of origin "Siurana" using excitation-emission fluorescence spectroscopy and three-way methods of analysis
}

\author{
By Francesca Guimet ${ }^{\star}$, Ricard Boqué and Joan Ferré
}

\author{
Department of Analytical Chemistry and Organic Chemistry, Rovira i Virgili University \\ $\mathrm{C} /$ Marcel.lí Domingo, s/n, E-43007 Tarragona, Catalonia, Spain \\ E-mail address: francesca.guimet@urv.net. Tel: +34-977-55-82-95. Fax: +34-977- 55-84-46
}

\section{RESUMEN}

Estudio de aceites de la denominación de origen protegida "Siurana" mediante espectroscopia de fluorescencia de excitación-emisión y métodos de análisis de tres vías.

La zona de producción de aceites de oliva de la Denominación de Origen Protegida (D.O.P.) "Siurana" puede dividirse en dos regiones: "Montsant" y "Camp de Tarragona", con distinta orografía, características del suelo y condiciones climáticas. Estas diferencias dan como resultado aceites con distinta estabilidad. Aquí se muestra que esta diferente estabilidad puede detectarse por fluorescencia de excitación-emisión. Los aceites de la región "Montsant" (más estables) muestran mayor intensidad de fluorescencia por encima de $500 \mathrm{~nm}$ (debido a la vitamina E) y menos por debajo de $500 \mathrm{~nm}$ (debido a productos de oxidación) que los procedentes de "Camp de Tarragona". Mediante el método de regresión por mínimos cuadrados parciales discriminante sobre la matriz desplegada se logró discriminar entre aceites de las dos regiones D.O.P. "Siurana", obteniéndose un porcentaje de clasificación correcta del $94 \%$ para aceites "Siurana-Camp" y del 100\% para aceites "Siurana-Montsant".

PALABRAS-CLAVE: Aceite de oliva virgen, D.O.P. "Siurana", Espectroscopia de fluorescencia, Métodos de análisis de tres vías, Mínimos cuadrados parciales.

\section{SUMMARY}

Study of oils from the protected denomination of origin "Siurana" using excitation-emission fluorescence spectroscopy and three-way methods of analysis.

The production area of the Protected Denomination of Origin (P.D.O.) "Siurana" olive oils can be divided into two regions: "Montsant" and "Camp de Tarragona", with different orography, soil characteristics and climatic conditions. As a result of these differences, the oils have variable stability. Here we show that excitation-emission fluorescence can detect these variations. Oils from the "Montsant" region (more stable) show more fluorescence intensity above $500 \mathrm{~nm}$ (due to vitamin E) and less below $500 \mathrm{~nm}$ (due to oxidation products) than those from the "Camp de Tarragona" region. Discrimination between oils from the two P.D.O. "Siurana" regions was achieved by means of discriminant unfold partial least squares regression, giving a percentage of correct classification of $94 \%$ for "Siurana-Camp" and $100 \%$ for "Siurana-Montsant" oils.

KEY-WORDS: Fluorescence spectroscopy, Partial least squares, P.D.O. "Siurana", Three-way methods of analysis, Virgin olive oil.

\section{INTRODUCTION}

Olive oil is an important food product, especially in Mediterranean countries, and its characterisation is an issue of current interest. At present, there is no single analytical index for characterising it, and numerous physical and chemical parameters (such as free acidity, peroxide value, $\mathrm{K}_{232}$ and $\mathrm{K}_{270}$ among others) must be measured to determine its geographical origin and/or olive variety (Aparicio, 1988; Tous et al., 1997; Lanteri et al., 2002; Marini et al., 2004). This requires the application of several techniques, such as chromatographic and spectroscopic, which often have the problem of being time-consuming. Other techniques (e.g. headspace-mass spectrometry (Marcos et al., 2002) and nuclear magnetic resonance (Sacchi et al., 1998)) have also been applied for this purpose. However some of them are not always present in the quality control laboratories. Fluorescence spectroscopy has also been applied to assess the authenticity of olive oils (Kyriakidis and Skarkalis, 2000; Sayago et al., 2004). The main advantages of this technique are that no complex sample preparation is required and that it is very fast. With excitation-emission fluorescence spectroscopy (EEFS) a set of fluorescence spectra can be recorded at different excitation wavelengths $\left(\lambda_{\text {ex }}\right)$ yielding an excitation-emission data matrix (EEM). Such amount of data enables more information to be obtained compared to when a single spectrum is measured. There are some examples of the application of EEFS to olive oils in the literature (Scott et al., 2003; Guimet et al., 2004 a, b). Multivariate chemometric methods have been widely applied to the data obtained from analytical techniques in order to differentiate between olive oil cultivars and/or varieties (Armanino et al., 1989; Boggia et al., 2002; Lanteri et al., 2002; Marini et al., 2004).

Spain is one of the most important olive oil producers and currently has nine protected denominations of origin (P.D.O.) (five in Andalusia, 
two in Catalonia, one in Castilla La Mancha and one in Aragon). The P.D.O. label defines the origin of the oils and the varieties used and guarantees the production and transformation of the product in its geographic areas. The products included in the same P.D.O. have some exceptional characteristics in common, including both analytical specifications and organoleptic properties. In this work we focus on olive oils from the P.D.O. "Siurana". The P.D.O. "Siurana" production area is a strip of the province of Tarragona, in Catalonia (Spain). "Siurana" oils, which are mainly obtained from arbequina olives (more than 90\%), may also contain small proportions of royal and morruda varieties. The physicochemical characteristics of "Siurana" oils, such as fatty acids, polyphenols, and stability vary depending on several factors. One of the most important is the state of ripeness of the olives. The geographical origin of olives (which includes orography, soil characteristics and climatic conditions) also has great influence (Tous et al., 1997). The P.D.O. "Siurana" production area can be divided into two regions: one inner and mountainous region, which is denominated "Montsant" and another closer to the sea, which is denominated "Camp de Tarragona". "Siurana-Montsant" (SM) oils have more phenolic compounds and oleic acid content and less linoleic acid content than Siurana-Camp (SC) oils. This makes SM oils more stable against oxidation than SC oils. These two types of oils also have different sensory properties. SM oils are in general more bitter and their colour is more intense, whereas SC oils are sweeter and more fluid. The differences between SM and SC oils are explained in more detail elsewhere (Tous et al., 1997).

In this paper we show the potential of the rapid technique EEFS to differentiate between oils from the two regions of P.D.O. "Siurana". The discriminant unfold partial least squares regression method (DU-PLSR) was applied because of its ability to discriminate.

\section{EXPERIMENTAL}

\subsection{Samples}

29 extra virgin olive oils from de P.D.O. "Siurana" were analysed. Samples 1-16 came from the SC region and samples 17-29 came from the SM region. All the samples analysed came mainly from arbequina olives and were obtained during the same harvesting year (2003). The ripeness stage of the two sets of olives was similar. Table 1 shows the

Table 1

Samples and their locality of origin

\begin{tabular}{|c|c|c|}
\hline $\begin{array}{l}\text { Sample } \\
\text { number }\end{array}$ & Origin & Region \\
\hline 1,10 & La Selva del Camp & $\mathrm{SC}$ \\
\hline $2-4$ & Reus & $\mathrm{SC}$ \\
\hline 5 & Llorenç del Penedès & $\mathrm{SC}$ \\
\hline 6 & Valls & $\mathrm{SC}$ \\
\hline 7 & Alcover & $\mathrm{SC}$ \\
\hline 8 & Constantí & $\mathrm{SC}$ \\
\hline 9,16 & La Canonja & $\mathrm{SC}$ \\
\hline 11 & Maspujols & $\mathrm{SC}$ \\
\hline 12 & Alforja & $\mathrm{SC}$ \\
\hline 13 & Les Borges del Camp & $\mathrm{SC}$ \\
\hline 14 & Almoster & $\mathrm{SC}$ \\
\hline 15 & Castellvell & $\mathrm{SC}$ \\
\hline 17,18 & Ulldemolins & SM \\
\hline 19 & La Serra d Almos & SM \\
\hline 20 & La Bisbal de Falset & $\mathrm{SM}$ \\
\hline 21 & Margalef & $\mathrm{SM}$ \\
\hline 22 & Cabacés & $\mathrm{SM}$ \\
\hline 23 & La Vilella Alta & SM \\
\hline 24 & Marçà & SM \\
\hline 25 & Capçanes & SM \\
\hline 26 & Falset & $\mathrm{SM}$ \\
\hline 27 & El Masroig & SM \\
\hline 28 & El Molar & $\mathrm{SM}$ \\
\hline 29 & La Palma d Ebre & $\mathrm{SM}$ \\
\hline
\end{tabular}


place of origin of the samples. The oils were stored in amber glass bottles under a nitrogen atmosphere at $7{ }^{\circ} \mathrm{C}$ and were analysed without any prior treatment. All samples were measured in duplicate.

\subsection{Instrumentation and software}

EEMs were measured with an Aminco Bowman series 2 luminescence spectrometer equipped with a $150 \mathrm{~W}$ xenon lamp and $10 \mathrm{~mm}$ quartz cells. The instrument detector was operated using the EmL/Ref channel and applying a $600 \mathrm{~V}$ voltage. Excitation and emission ranges were $\lambda_{\mathrm{ex}}=300-390 \mathrm{~nm}$ and $\lambda_{\mathrm{em}}=$ 415-600 nm, respectively. Measuring emission above excitation prevented Rayleigh scatter. The step size and bandpass of both monochromators were $5 \mathrm{~nm}$ and $4 \mathrm{~nm}$, respectively. The scan rate was $30 \mathrm{~nm} \mathrm{~s}^{-1}$. The instrument software was used to correct the EEMs for deviations in the ideality of the lamp, monochromators and detector (Lakowicz, 1999).

Data were exported to ASCll code and processed with Matlab software (version 6.5) (Matlab, 2002) and the PLS-Toolbox (version 3.0) (PLS-Toolbox, 2003).

\section{RESULTS AND DISCUSSION}

\subsection{Spectra}

In the range studied $\left(\lambda_{\mathrm{ex}}=300-390 \mathrm{~nm} ; \lambda_{\mathrm{em}}=\right.$ 415-600 nm) (Fig. 1), the main fluorescent compounds present in virgin olive oils are vitamin $E$, which emits around $\lambda_{\mathrm{em}}=525 \mathrm{~nm}$ and oxidation

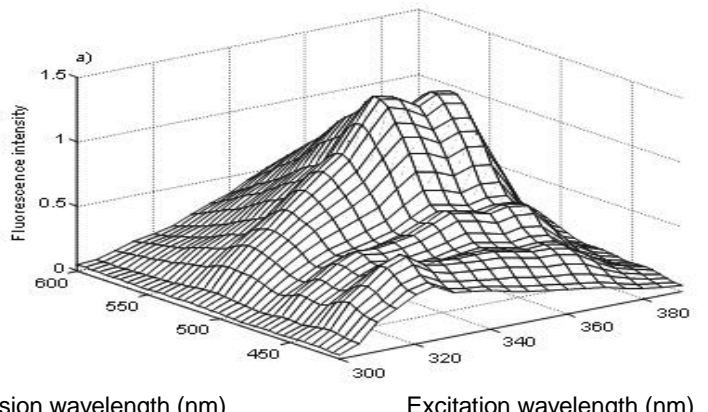

Emission wavelength $(\mathrm{nm}) \quad$ Excitation wavelength $(\mathrm{nm})$

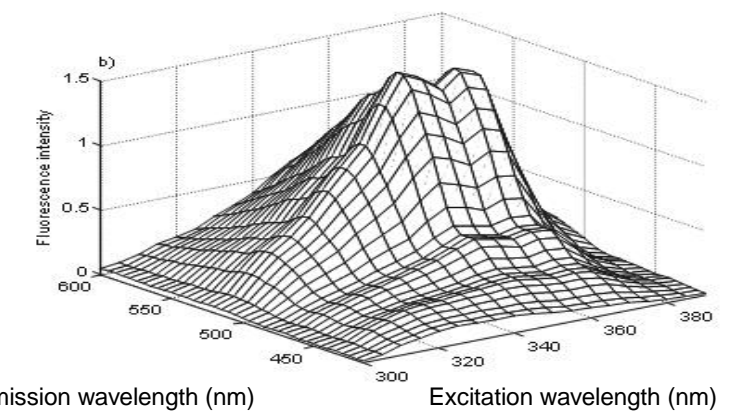

Figure 1

Average EEMs between $\lambda_{\mathrm{ex}}=300-390 \mathrm{~nm} ; \lambda_{\mathrm{em}}=415-600 \mathrm{~nm}$ : (a) "Siurana-Camp"; (b) "Siurana-Montsant" oils. products (conjugated hydroperoxides formed as a result of fatty acids oxidation by oxygen), which give rise to two low peaks around $\lambda_{\mathrm{em}}=445$ and $\lambda_{\mathrm{em}}=475$ $\mathrm{nm}$ (Kyriakidis and Skarkalis, 2000). The inspection of the EEMs of the samples reveals that the two types of "Siurana" oils have different fluorescence. SC oils tend to have less intensity at emissions above $500 \mathrm{~nm}$ (vitamin E) and more intensity at emissions below $500 \mathrm{~nm}$ (oxidation products) than SM oils. A large content of oxidation products indicates a major degradation of the oils, whereas vitamin $E$ contributes to stability, because of its antioxidant effect. Thus, the trend seen on the EEMs agrees with the fact that SM oils are more stable than SC oils.

In order to check if the differences between the mean spectra plotted in Figure 1 were statistically significant, we applied the Hotelling's $\mathrm{T}^{2}$ statistic (Krzanowski, 2000). For applying this test, the mean values of the two replicates of each sample were used. The EEMs were unfolded in such a way that all the emission spectra of each EEM were concatenated in a row. Thus, for each sample a row-vector of size $(1 \times 722)$ was obtained, where 722 is the product $\lambda_{e} \times \lambda_{\mathrm{em}}$. As the number of variables was superior to the number of samples, principal component analysis (PCA) was computed to reduce dimensionality. The Hotelling's $\mathrm{T}^{2}$ statistic was applied on the scores of the PCA model using five PCs. The calculated $F$ was $F_{\text {cal }}=18.21$ and it was compared to the critical $F$-value for a two-sided test at $=0.05\left(F_{\text {tab }}\right.$ $=3.15$ ). As $F_{\text {cal }}$ was higher that the critical F-value, we can conclude that the mean spectra of the two "Siurana" regions are statistically different. However, the differences between the EEMs of the two groups of oils were not obvious for all the samples. For this reason, chemometric methods were applied for discrimination.

\subsection{Discriminant unfold partial least squares regression (DU-PLSR)}

Partial least squares regression (PLSR) is a calibration method widely used in multivariate analysis. The regression is based on factors determined by employing both the independent variables $(\mathbf{X})$ and the variable to be predicted $(\mathbf{y})$. Discriminant partial least squares regression (D-PLSR) is a particular case of PLSR in which the variable to be predicted is the membership or no-membership of the samples to a particular class.

Before applying D-PLSR, an $\mathbf{X}$ matrix containing the unfolded EEMs of the samples was built (i.e. each row consisted of all the fluorescence spectra measured for one sample concatenated). Then, the method applied to this matrix is named DU-PLSR. The size of $\mathbf{X}$ was $58 \times 722$ (samples (in duplicate) $x$ $\left.\left(\lambda_{\mathrm{em}} \times \lambda_{\mathrm{ex}}\right)\right)$. The matrix was column mean-centered. 


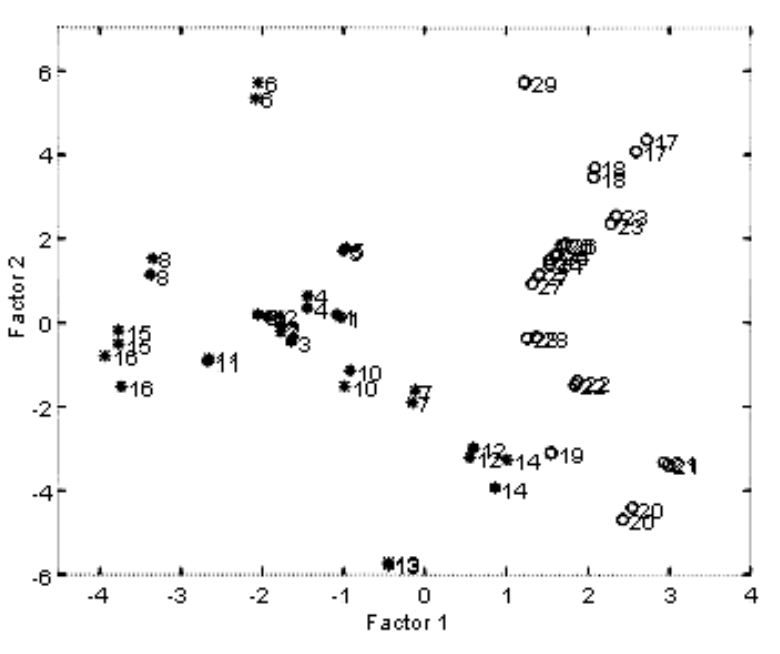

Figure 2

Score plot from DU-PLSR to the EEMs of the "Siurana" olive oils. $\left(^{*}\right)$ SC oils, (o) SM oils.

Then we built a regression model $\mathbf{y}=f(\mathbf{X})$ where $\mathbf{y}$ was a class variable made up of a column with zeros for SC oils (class 0 ) and ones for SM oils (class 1 ). The optimal number of factors, selected by leave-two-out cross-validation, was two. The explained variance by the two factors was $93 \%$ of $\mathbf{X}$ and $76 \%$ of $\mathbf{y}$. Figures $2-3$ show the score and loading plots of DU-PLSR. The loadings were folded back. The score plot (Fig. 2) shows that factor 1, which has 33\% expl. var. of $\mathbf{X}$ and $71 \%$ expl. var. of $\mathbf{y}$, is the most discriminating between the two types of oils, because SM oils tend to have scores higher than 1 on this factor and SC oils tend to have scores lower than 1. However, some of the samples are not well separated along factor $1(12,14,19,27,28$, and 29). As far as factor 2 is concerned, there is no discrimination between the "Siurana" regions. These results can be interpreted by looking at the loadings (Fig. 3). Factor 1 loadings have two differentiated regions: a positive zone at emissions above $500 \mathrm{~nm}$ (due to the influence of vitamin E) and a negative zone at emissions below $500 \mathrm{~nm}$ (due to oxidation products). The larger value of the loadings in the negative zone indicates that oxidation products have more influence than vitamin $\mathrm{E}$ on this factor. A closer inspection of the EEMs revealed that the main differences between the two "Siurana" types of oils lie in the fluorescence below $\lambda_{\mathrm{em}}=500 \mathrm{~nm}$ (the oxidation products emission region), whereas the differences in vitamin $E\left(\lambda_{\text {em }}\right.$ above $\left.500 \mathrm{~nm}\right)$ are less obvious. This explains the greater weight of oxidation products on the most discriminant factor of DU-PLSR. Thus, the negative scores on factor 1 of most of SC oils indicate that they are more deteriorated than SM oils. On the contrary, high scores in factor 1 indicate more stability of the oil
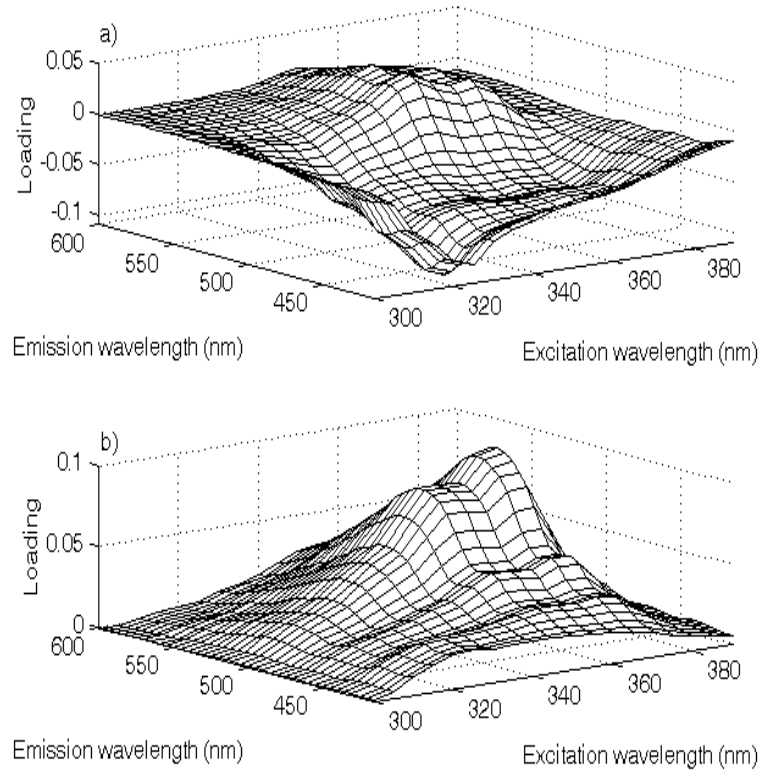

Figure 3

Refolded loadings from DU-PLSR to the EEMs of the "Siurana" olive oils. (a) factor 1 ; (b) factor 2.

(high content of vitamin $\mathrm{E}$ and low of oxidation products).

Samples 12 and 14 are located on the boundary between the two classes, having scores close to one in factor 1 (Fig. 2). The peculiar behaviour of samples 12 and 14 is due to the fact that their EEMs are very similar to those of samples 19, 20 and 21, whose region below $\lambda_{\mathrm{em}}=500 \mathrm{~nm}$ is almost flat. This indicates a very low content of oxidation products. This can be due to several factors, e.g., a greater stability or better storage. In addition, the whole intensity of these EEMs was not very high. In spite of the membership of sample 12 to the SC region, it is very close to the SM region. This may explain its position on the score plot (Fig. 2). For sample 14, the reason is less obvious, but the shape of its fluorescence EEMs indicates that this sample has been slightly deteriorated.

Factor 2 was seen to be correlated to the whole fluorescence intensity of the oils. Thus, the most intense EEMs (samples 6 and 29) had the largest scores for this factor and the less intense EEM (sample 13) had the lowest scores. From the score plot (Fig. 2), it can also be observed that repeatability of the measurements was quite good, because the duplicates of the samples appear very close each other. In order to check the precision of the method, we applied analysis of variance (ANOVA) to the score matrix. $\operatorname{Var}_{\text {within }}$ indicates the percentage of variance between the pairs of replicates, and var $_{\text {between }}$ indicates the percentage of variance between samples. Both values are referred to the total variability. These values were var $_{\text {within }}=0.2 \%$ and var $_{\text {between }}=99.8 \%$ in relative terms. From these results, we can conclude that the precision of the 
method was acceptable, because the variability between replicates is much smaller than the variability between samples.

Figure 4 shows the predicted vs. reference values obtained by cross-validation from DU-PLSR for the two-factor model. The oils were assigned to the SC class when the predicted $\mathbf{y}$ was lower than 0.5. Oils with a predicted value higher than 0.5 were assigned to the SM class. Under this criterion, the percentage of correct classification was $94 \%$ for SC oils and $100 \%$ for SM oils. Only sample 14 was misclassified. The root mean square error of cross-validation (RMSECV) was 0.27.

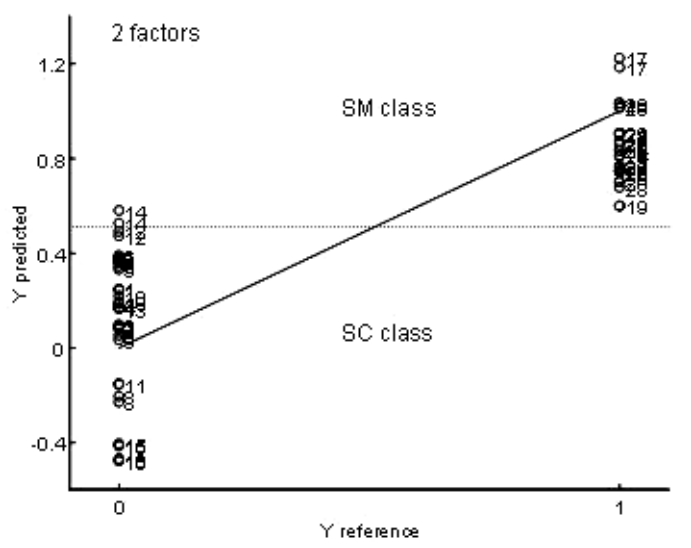

Figure 4

Predicted vs. reference values obtained by cross-validation from DU-PLSR (2 factors). The straight line is the ideal regression line. The broken line (- - -) identifies the boundary between classes.

Besides concatenating the data matrices to form a larger matrix, they can also be arranged in a three-dimensional structure. The D-PLSR method applied to the data arranged in this way is named discriminant multi-way partial least squares regression (DN-PLSR). We checked if the results obtained from DU-PLSR could by improved by using DN-PLSR. Thus, the oil EEMs were stacked on a three-way array of size $58 \times 38 \times 19$ (samples (in duplicate) $\times \lambda_{\text {em }} \times \lambda_{\text {ex }}$. Then the three-way array was centred along the first mode (samples) and DN-PLSR was computed on it. The class variable was defined as in DU-PLSR. The optimal number of factors, selected by leave-two-out cross-validation was two (90\% expl. var. of $\mathbf{X}$ and $76 \%$ expl. var. of $\mathbf{y})$. The results did not improve compared to DU-PLS. The percentages of correct classification were $91 \%$ for SC oils and $100 \%$ for SM oils. The two replicates of sample 14 were misclassified and one replicate of sample 12 was in the boundary between the classes $(\mathbf{y}=0.5)$.

\section{CONCLUSIONS}

This work has shown the potential of EEFS and three-way methods of analysis for discriminating between the two types of "Siurana" olive oils. The different orography, soil characteristics and climatic conditions of the SC and SM regions lead to olive oils with different chemical composition, which can be detected by fluorescence spectroscopy. The higher stability of SM oils causes them to have lower contents of oxidation products. This implies that SM emits much less fluorescence at emissions below $500 \mathrm{~nm}$ compared to SC, which are more deteriorated. In addition, SM oils tend to have a higher content of vitamin $\mathrm{E}$ (emissions above 500 $\mathrm{nm})$.

Using DU-PLSR enabled us to discriminate between the two types of "Siurana" oils with a percentage of correct classification of $94 \%$ for SC oils and $100 \%$ for SM oils, with only one misclassified sample. This method also showed the good repeatability of the measurements.

\section{ACKNOWLEDGEMENTS}

We would like to thank the Spanish Ministry of Science and Technology (project $\mathrm{n}^{\circ}$ BQU200301142) for financial support and the Rovira i Virgili University for a doctoral fellowship.

\section{REFERENCES}

Aparicio R. 1988. Characterization of foods by inexact rules: the SEXIA expert system. J. Chemom. 3, 175-1988.

Armanino C, Leardi R, Lanteri S, Modi, G. 1989. Chemometric analysis of Tuscan olive oils. Chemom. Intell. Lab. Syst. 5, 343-354.

Boggia R, Zunin P, Lanteri S, Rossi N, Evangelisti, F. 2002. Classification and class-modelling of "Riviera Ligure" extra-virgin olive oil using chemical-physical parameters. J. Agric. Food Chem. 50, 2444-2449.

Guimet F, Ferré J, Boqué R, Rius, FX. 2004 a. Application of unfold principal component analysis and parallel factor analysis to the exploratory analysis of olive oils by means of excitation-emission matrix fluorescence spectroscopy. Anal. Chim. Acta 515, 75-85.

Guimet F, Boqué R, Ferré J. 2004 b. Cluster analysis applied to the exploratory analysis of commercial Spanish olive oils by means of excitation-emission fluorescence spectroscopy. J. Agric. Food Chem. 52, 6673-6679.

Krzanowski W.J. 2000. Principles of Multivariate Analysis. A user's perspective, Oxford University Press, Oxford.

Kyriakidis NB, Skarkalis P. 2000. Fluorescence spectra measurement of olive oil and other vegetable oils. $J$. AOAC Int. 83, 1435-1439.

Lakowicz J.R. 1999. Principles of Fluorescence Spectroscopy, 2nd ed., Kluwer Academic/Plenum Publishers, New York.

Lanteri S, Armanino C, Perri E, Palopoli, A. 2002. Study of oils from Calabrian olive cultivars by chemometric methods. Food Chemistry 76, 501-507.

Marcos I, Pérez JL, Fernández ME, García C, Moreno B, Henriques LR, Peres MF, Imões MP, Lopes PS. 2002. Application of headspace-mass spectrometry for differentiating sources of olive oil. Anal. Bional. Chem. 374, 1205-1211. 
Marini F, Balestrieri F, Bucci R, Magrì AD, Magrì AL, Marini D. 2004. Supervised pattern recognition to authenticate Italian extra virgin olive oil varieties. Chemom. Intell. Lab. Syst. 73, 85-93.

Matlab. The Mathworks, South Natick, MA, USA 2002. http://www.mathworks.com, last access: 30/03/05.

PLS-Toolbox. Toolbox for Matlab by Eigenvector Research, Inc. 2003. http://www.eigenvector.com/, last access: 30/03/05

Sacchi R, Mannina L, Fiordiponti P, Barone P, Paolillo L, Patumi M, Segre, A. 1998. Characterization of Italian extra virgin olive oils using ${ }^{1} \mathrm{H}-\mathrm{NMR}$ spectroscopy. $J$. Agric. Food Chem. 46, 3947-3951.
Sayazo A, Morales MT, Aparicio R. 2004. Detection of hazelnut oil in virgin olive oil by a spectrofluorimetric method. Eur. Food Res. Technol. 218, 480-483.

Scott SM, James D, Ali Z, O'Hare WT, Rowell FJ. 2003. Total luminescence spectroscopy with pattern recognition for classification of edible oils. Analyst 128, 966-973.

Tous J, Romero A, Plana J, Guerrero L, Díaz I, Hermoso JF. 1997. Características químico-sensoriales de los aceites de oliva "Arbequina" obtenidos en distintas zonas de España. Grasas Aceites 48, 415-424.

Recibido: Noviembre 2004 Aceptado: Mayo 2005 